\title{
SOCIOLOGIA DO DIREITO EM VERSUS COM A DOGMÁTICA JURÍDICA 3?
}

Artur Stamford da Silva (Editor)

Este número 3, encerra nosso volume 5, referente ao ano de 2018, ano no qual - durante o Encontro Anual do Comitê de Pesquisa de Sociologia do Direito da ISA, realizado em Lisboa no período de 10 a 14 de setembro - teve lugar o Painel: 1132 Socio-Legal Journals in a Changing Global Editorial Field, coordenada por Pierre Guibentif (DINÂMIA'CET-IUL, ISCTE-IUL), os expositores foram Laurence Dumoulin (Droit et Société), Jiri Priban (Journal of Law and Society), Susan Sterett (Law \& Society Review), Artur Stamford da Silva (Revista Brasileira de Sociologia do Direito), Letizia Mancini (Sociologia del Diritto) e Michelle Cottier (Zeitschrift für Rechtssoziologie).

Na convocatória desta mesa, Guibentif lançou dez pontos ao debate: 1ำ) que as Revistas estão cada vez sendo mais consultadas on-line; 2ㅇ) que há uma concentração em artigos individuais; 3 ㅇ) a influência dos novos meios de comunicação na perspectiva científica (blogs etc.); 4ㅇ) os desafios que Editores multinacionais, agências de indexação promovem à manutenção e sobrevivência dos periódicos; 5) o desafio de se defender a profissionalismo na produção científica; 6ㅇ) as barreiras na publicação em outros idiomas além do inglês; 7으) os desafios de se publicar em periódicos especializados; 8ㅇ) o problema das identidades disciplinares; 9) a questão da avaliação da atividade científica; 10) a cooperação entre autores e a competição entre periódicos.

As exposições e os debates consequentes apontaram como dificuldades e desafios centrais da sociologia do direito a identidade da área como espaço de debate no direito, isolamento dos pesquisadores da área, os desafios de manter periódicos especializados em sociologia do direito, que critérios aplicar para que um artigo submetido seja classificado com sociológico do direito. Não se tratou de buscar respostas, mas conhecer como cada um dos editores vivem tais dificuldades e desafios. Ainda que não haja resposta para a questão da identidade disciplinar, ficou patente que é possível considerar um artigo como não sociológico do direito, por mais que isso não dependa de uns tantos critérios, mas sim de a abordagem conter reflexões críticas. A proposta de se estabelecer uma agenda para a sociologia do direito não teve repercussão, diria porque há não cabe falar na sociologia do direito como saber identificado como a cientificidade do direito, mas sim, o desafio da sociologia do direito está em dialogar com os demais saberes jurídicos e não jurídicos.

Nesta publicação, compartilho a alegria vivida quando Cláudio Souto ligou para conversar sobre seus trabalhos e suas reflexões recentes. Não podia ter outro resultado que convidá-lo a reduzir a termo suas reflexões nos abrilhantar com a publicação de suas ideias, afinal, Cláudio Souto configura como o criador da disciplina Sociologia do Direito nos cursos de direito, no Brasil, por, em 1959, ter ministrado um curso de sociologia do direito, com isso, institucionaliza a disciplina.

Como já escrito nos números anteriores, o tema das apresentações da RBSD para 2018 foi a relação sociologia do direito e dogmática jurídica e nada mais condizente que publicarmos as reflexões atuais de Cláudio Souto. Autor que dedicou sua vida profissional à sociologia do direito, além de crítico é um promotor e provocador de inquietações sobre a referida relação. Desde seus primeiros escritos já afirmava a insuficiência da dogmática para lidar com o direito. Lança a teoria substantiva do direito, defendendo que o composto SIV é o elemento primordial para uma compreensão e explicação do direito, afinal, o ser humano é constituído de Sentimentos, ideias e vontades (SIV).

Para Cláudio Souto "a Dogmática Jurídica, na medida em que não apresenta hipóteses a serem testadas pela observação controlada da realidade empírica, tem um grau de cientificidade bastante reduzido e desprovido de qualquer nível de rigor em suas afirmações substantivas. Isso, evidente, não quer dizer que 
não possa apresentar um acentuado rigor lógico-formal - rigor esse que Max Weber enfatiza. Já a Sociologia do Direito é saber científico-social do jurídico cujas hipóteses são controladas ou controláveis por métodos e técnicas, tanto quanto possível, rigorosos, de pesquisa empírica" (SOUTO, Cláudio. Ciência e saberes jurídicos: enfrentando o objeto. In: Artur Stamford da Silva. Sociologia do direito: na prática da teoria. Curitiba: Juruá, 2007. p. 19-38).

Obrigado, Cláudio, por aceitar nossa provocação e dar o prazer e a honra de publicar suas ideias. 0 exemplo de pessoa, de seriedade na vida acadêmica, de aposta na cientificidade do direito, de dedicação à sociologia do direito fica aqui registrado quanto em 2018 Cláudio segue dedicado à produção de científica.

Na sequência, agradeço Kathya Araújo pelos tratos com a liberação de publicação de seu artigo central para a sociologia do direito, principalmente para a América Latina, pois aborda a relação com as normas nessa sociedade. Texto criativo e com perspectiva teórica novidosa e própria, estabelecendo um marco teórico para a sociologia jurídica das normas.

Antes de tratar dos demais artigos, aproveito para compartilhar também a alegria de publicarmos nossa primeira RESENHA, ainda mais quando se trata de obra de um autor central da sociologia jurídica, como se configura Boaventura de Sousa Santos, e uma obra de leitura indispensável para o momento atual: Para uma revolução democrática da Justiça.

Neusa Schnorrenberger e Rosângela Angelin apoiam e ajudam a BRSD com artigo sobre Mulheres camponesas no Brasil. Denunciar a lógica do patriarcado e a manutenção de violência contra mulher como algo cultural é traço que a sociologia do direito escreve em sua história. $\mathrm{O}$ artigo explora a literatura atual e traz contribuições para se pensar a questão servindo para auxiliar a dogmática jurídica, afinal, problemas como distribuição de renda não são exclusivos da economia.

Em "Legitimidade e Poder: conhecendo o ordenamento não jurídico por meio da análise de discurso", Carolline Leal Ribas demonstra a importância da análise do discurso como via de pesquisa sobre a lógica jurídica presentes nas favelas. Remota a importância do pluralismo jurídico, com Wolkmer, ao explorar temas do urbanismo como o direito à moradia, em foco diante dos últimos acontecimentos no Brasil, em especial em São Paulo.

Seguindo, Alexsandra Gato Rodrigues e José Francisco Dias da Costa Lyra abordam tema que não pode ser negligenciado pela sociologia do direito, principalmente quando estamos voltando ao debate da sua relação com a dogmática jurídica: a mediação judicial.

Gênero, tema que está em cena principalmente com o debate educacional, temos uma aplicação do método marxista, em espacial com Evgeni Pachukanis, sobre a teoria geral do direito. É o que lemos no artigo de Thamíris Evaristo Molitor em seu trabalho dedicado à posição da mulher em nossa sociedade.

Autor que reputo negligenciado no Brasil, Roberto Mangabeira Unger é trabalhado por Alexandre Santos Sampaio para lidar com a socialdemocracia, a poliarquia radical e a democracia mobilizadora.

Maiquel Ângelo Dezordi Wermuth e Luana Marina Santos, no artigo Biopoder e resistência: a (bio)potência da multidão, dão voz a Michel Foucault ao abordar a questão da relação do indivíduo com o social sob a pressão do coletivo, da multidão. $O$ texto, se lido e relacionado ao texto de Kathya Araújo viabiliza reflexões indispensáveis para se observar como, distintas abordagens, podem levar a resultados de pesquisa semelhantes.

Com David Barbosa de Oliveira e Vinicius Madureira Maia lemos Niklas Luhmann no Brasil: resistências acadêmicas ao estudo da teoria dos sistemas, expondo elementos da teoria e críticos da perspectiva, principalmente quanto à perspectiva ontológica presente no "anti-humanismo metodológico" luhmaniano.

Por fim, no artigo "A insuficiência de diferenciação funcional observada a partir da crise no cenário brasileiro" Matheus Figueiredo Nunes de Souza e Fernando Tonet tratam da questão da diferenciação funcional como vetor à análise e compreensão da modernidade periférica.

Sigamos em pesquisa sociológica do direito, fazendo ciência do direito sem VERSUS! 